\title{
Update on pulmonary hypertension complicating chronic obstructive pulmonary disease
}

This article was published in the following Dove Press journal:

International Journal of COPD

7 September 2009

Number of times this article has been viewed

\section{Soma Jyothula \\ Zeenat Safdar}

Pulmonary-Critical Care Medicine, Baylor College of Medicine, Houston, TX, USA
Correspondence: Zeenat Safdar

Assistant Professor of Medicine,

Pulmonary-Critical Care Medicine,

Baylor College of Medicine, Houston,

TX 77030, USA

$\mathrm{Tel}+\mathrm{I} 7137982400$

Fax +I 7137982688

Email safdar@bcm.edu
Abstract: Pulmonary hypertension (PH) is the hemodynamic manifestation of various pathological processes that result in elevated pulmonary artery pressures (PAP). The National Institutes of Health Registry defined pulmonary arterial hypertension as the mean PAP of more than $25 \mathrm{~mm} \mathrm{Hg}$ with a pulmonary capillary wedge pressure or left atrial pressure equal to or less than $15 \mathrm{~mm} \mathrm{Hg}$. This definition remains the currently accepted definition of PH that is used to define $\mathrm{PH}$ related to multiple clinical conditions including chronic obstructive pulmonary disease (COPD). The estimated US prevalence of COPD by the National Health Survey in 2002 in people aged $>25$ was 12.1 million. There is a lack of large population-based studies in COPD to document the correct prevalence of PH and outcome. The major cause of PH in COPD is hypoxemia leading to vascular remodeling. Echocardiogram is the initial screening tool of choice for $\mathrm{PH}$. This simple noninvasive test can provide an estimate of right ventricular systolic and right atrial pressures. Right heart catheterization remains the gold standard to diagnose $\mathrm{PH}$. It provides accurate measurement of mean PAP and pulmonary capillary wedge pressure. Oxygen therapy remains the cornerstone therapeutic for hypoxemia in COPD patients. Anecdotal reports suggest utility of PDE5-inhibitors and prostacyclin to treat COPD-related PH. Large randomized clinical trials are needed before the use of these drugs can be recommended.

Keywords: pulmonary arterial hypertension, airflow obstruction, vascular remodeling

\section{Introduction}

Pulmonary hypertension (PH) is the hemodynamic manifestation of various pathological processes that result in elevated pulmonary artery pressures (PAP). ${ }^{1,2}$ The current hemodynamic definition of $\mathrm{PH}$ is a mean PAP $>25 \mathrm{~mm} \mathrm{Hg}$ with a pulmonary capillary wedge pressure (PCWP), left atrial pressure or left ventricular end-diastolic pressure $\leq 15 \mathrm{~mm} \mathrm{Hg}$ and pulmonary vascular resistance (PVR) $>3$ Wood units. These criteria define $\mathrm{PH}$ associated with multiple other disease processes including chronic obstructive pulmonary disease (COPD). ${ }^{3}$ In the current discussion, we will use this definition to define $\mathrm{PH}$ associated with COPD.

\section{Epidemiology}

COPD is a global disease caused by chronic exposure to airway irritants, most commonly tobacco smoke. Emerging literature suggests role of other irritants like biofuel smoke. ${ }^{4,5}$ The functional hallmark of the disease is airflow obstruction. COPD usually presents with respiratory symptoms and is confirmed by spirometry. The Global initiative for Chronic Obstructive Lung disease (GOLD) has defined COPD as post-bronchodilator forced expiratory volume in one second $\left(\mathrm{FEV}_{1}\right) /$ forced vital 
capacity (FVC) $<70 .^{5}$ The disease is further classified into four stages based on calculated $\mathrm{FEV}_{1}$. The estimated US prevalence of COPD by the National Health Survey in 2002 in people aged $>25$ was 12.1 million. $^{6}$ The survey defined COPD as a positive response to the query "have you ever been told in the last 12 months by a doctor or health care professional that you have chronic bronchitis or emphysema". Two large population studies have reported the prevalence rates of COPD in multiple countries using GOLD criteria. Burden of obstructive disease initiative (BOLD) reported $10.1 \%$ as prevalence of COPD stage II or higher. ${ }^{7}$ The Latin American project for the investigation of obstructive lung disease (PLATINO) reported $7.8 \%$ to $20 \%$ in various sites in South America. ${ }^{8}$

The exact prevalence of $\mathrm{PH}$ in patients with COPD is unclear. ${ }^{9}$ The diagnosis of $\mathrm{PH}$ in COPD patients is difficult. The published studies differ not only in their definition but also conditions under which $\mathrm{PH}$ was reported (rest, exercise, and exacerbation). Oswald-Mammosser and colleagues performed right heart catheterization (RHC) on 151 patients with COPD. The definition of $\mathrm{PH}$ was mean PAP $\geq$ than $20 \mathrm{~mm} \mathrm{Hg}$ at rest and $\geq$ than $30 \mathrm{~mm} \mathrm{Hg}$ with exercise. $21 \%$ of subjects had $\mathrm{PH}$ at rest and $66 \%$ with exercise. ${ }^{10}$ PAP exhibited an inverse relationship with $\mathrm{FEV}_{1}$ and no relation to resting arterial oxygen saturation. Scharf and colleagues evaluated 120 patients recruited in the National Emphysema treatment trial (NETT). ${ }^{11}$ The authors stratified mean PAP into mild ( $\leq 20 \mathrm{~mm} \mathrm{Hg}$ ) moderate $(21-35 \mathrm{~mm} \mathrm{Hg})$ and severe $(>35 \mathrm{~mm} \mathrm{Hg})$ categories. Moderate mean PAP was noted in $85.8 \%$ of patients and severe in $5 \%$ of the subjects. ${ }^{11}$ Patients included in this study had more severe airway obstruction $\left(\mathrm{FEV}_{1} 27 \%\right)$ compared to prior study. ${ }^{10}$ Regression analysis showed diffusion capacity and FEV correlated with mean PAP. No relation between resting oxygen saturation and mean PAP was noted. Based on these studies an assumption can be made that worsening lung function is associated with increased incidence of PH. The burden of disease is probably high considering the high prevalence of COPD in various populations across the globe..$^{5,7,8}$ The nature of relationship between airway obstruction $\left(\mathrm{FEV}_{1}\right)$ and $\mathrm{PH}$ (defined by mean PAP) remains undefined.

Chaouat and colleagues evaluated 998 patients with COPD for presence of PH by RHC. Severe PH was defined as mean PAP $>40 \mathrm{~mm} \mathrm{Hg} .{ }^{12}$ Twenty-seven patients had mean PAP $>40 \mathrm{~mm} \mathrm{Hg}$ and 11(1.1\%) among these had COPD as the lone explanation. These patients were then compared to a control group of 30 COPD subjects. The control group had 16 patients with mean PAP $>20 \mathrm{~mm} \mathrm{Hg}$. The study group showed mild to moderate airway obstruction, severe hypoxemia, hypocapnia, and very low diffusion capacity. This study shows the low prevalence of severe PH in COPD.

Thabut and colleagues performed RHC in 115 patients with COPD. The subjects were evaluated for lung volume reduction surgery (LVRS) and lung transplantation. ${ }^{13} \mathrm{PH}$ (defined as mean PAP $>25 \mathrm{~mm} \mathrm{Hg}$ ) was present in $50.2 \%$. Moderate (mean PAP 35 to $45 \mathrm{~mm} \mathrm{Hg}$ ) in $9.8 \%$ and severe (mean PAP $>45 \mathrm{~mm} \mathrm{Hg}$ ) in $3.7 \%$ of patients. Mean PAP was related to arterial partial pressure of oxygen and alveolar-arterial oxygen gradient in multivariate analysis. 16 patients were noted with moderate airway limitation but strikingly elevated PAP. ${ }^{13}$ This study suggests a relatively high prevalence of $\mathrm{PH}$ in COPD patients, but severe $\mathrm{PH}$ is uncommon. The therapeutic implications of this finding are unclear currently.

The incidence of PH in COPD patients was evaluated by Kessler and colleagues. The authors performed a longitudinal study on 131 patients with COPD by performing serial RHC at baseline and than at follow-up (mean follow-up was $6.8 \pm 2.9$ years). ${ }^{14}$ All subjects had normal PAP at rest $(<20 \mathrm{~mm} \mathrm{Hg})$. They were divided into two groups based on presence or absence of elevated PAP with exercise ( $>30 \mathrm{~mm} \mathrm{Hg}$ ) $25 \%$ of patients developed PH on follow up and was mild by hemodynamic criteria (mean PAP 26.8 $\pm 6.6 \mathrm{~mm} \mathrm{Hg}$ ). Subjects who exhibited elevated PAP with exercise were more likely to exhibit resting PAP elevation upon follow up. The rate of progression was $+0.4 \mathrm{~mm} \mathrm{Hg}$ per year. In a recent study by Moran-Mendoza, information on wood smoke-associated lung disease and $\mathrm{PH}$ was obtained prospectively. Subjects with $>6$ months of exposure to wood smoke were followed for five years. Postmortem pathological evaluation revealed no difference when compared to smokers in the presence of emphysema/bronchitis and pulmonary vascular changes. PH was defined based on a radiological index (hilar/thorasic index $>38 \%$ ) and was found to be more marked in females exposed to wood smoke. ${ }^{15}$

With the sparse literature available on incidence and prevalence of COPD-related $\mathrm{PH}$, the following conclusions can be made. PH is usually mild in COPD and presence of severe $\mathrm{PH}(>40 \mathrm{~mm} \mathrm{Hg}$ ) should lead to further investigation for alternative etiologies. Although the pulmonary pressure elevations in the majority COPD-related $\mathrm{PH}$ cases are mild to moderate in nature, there seems to be a small but significant group of patients in whom $\mathrm{PH}$ is severe despite relatively moderate airflow obstruction. ${ }^{13}$ This group may represent a separate population of patients with features similar to 
patients with idiopathic PH. This may have significant prognostic and therapeutic implications.

\section{Pathogenesis of pulmonary hypertension in COPD}

Multiple animal and human experiments have tried to delineate the pathological processes involved in the development of PH in COPD (Figure 1). The central stimulus to these processes remains chronic exposure of airways to noxious stimuli like cigarette and biofuel smoke. Exposure to these stimuli is a known inciting agent of airway inflammation leading to obstructive airway disease. Current evidence suggests role of airway irritants in addition to chronic airway inflammation in pulmonary vascular alterations. Discussed below are the various pathological processes involved in the pathogenesis of $\mathrm{PH}$ in COPD.

\section{Hypoxia and hypercapnia}

Hypoxia induced pulmonary vasoconstriction is a protective response to keep ventilation-perfusion ratio optimum by shunting blood away from the hypoxemic areas. The traditional hypoxic model of $\mathrm{PH}$ is based on the hypothesis that chronic hypoxia initiates vascular remodeling leading to permanent changes in pulmonary vasculature. Studies performed in vitro elucidated the mechanisms underlying hypoxia driven vascular changes.

Barbera and colleagues evaluated COPD patients undergoing lung resection. ${ }^{16}$ Subjects were stratified based on airflow obstruction and response to $100 \%$ oxygen. Histological evaluation of the pulmonary vasculature showed increased wall thickness secondary to intimal hyperplasia and decreased lumen size. These changes were more marked in the group with blunted response to oxygen. Animal models have demonstrated that $\mathrm{PCO}_{2}$ and $\mathrm{pH}$ has an additive effect in augmenting vasoconstrictor response of hypoxia. This hypothesis was tested in an anesthetized open chest dog model and the flow difference measured. There was $8 \%$ difference in flow when end-tidal $\mathrm{PCO}_{2}$ was elevated in the presence of hypoxia, compared to hypoxia alone. ${ }^{17}$ Hypoxia may induce endothelial cells to release proliferate cytokine leading to cellular hypertrophy in the vessel wall and increase in extracellular matrix. These vascular changes

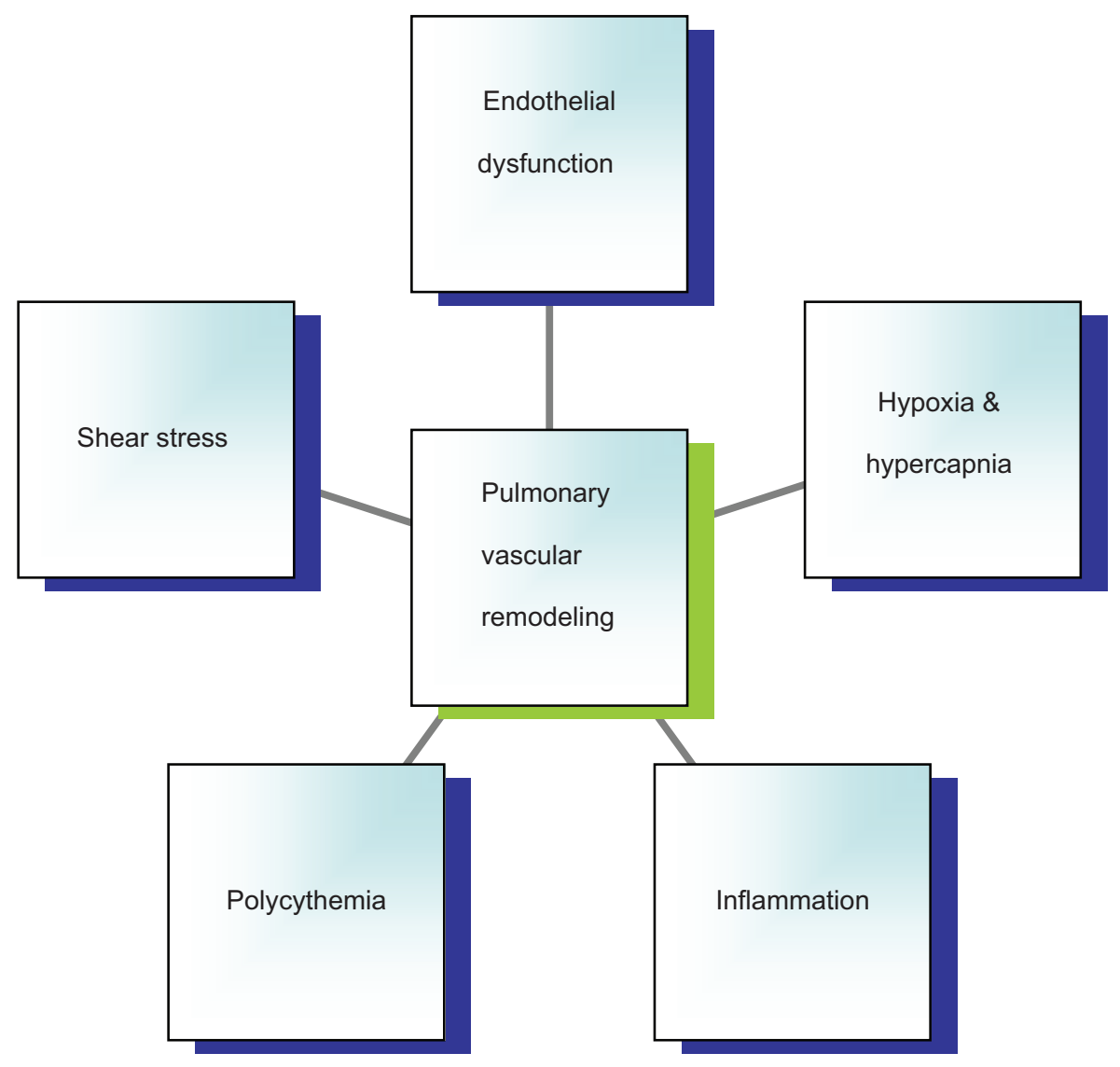

Figure I Potential mechanisms leading to pulmonary hypertension in COPD. Abbreviation: COPD, chronic obstructive pulmonary disease. 
contribute to vascular remodeling and putatively may have an effect on vascular dynamics leading to PH. These findings implicate a more complex mechanism than simple hypoxic vasoconstriction (which is the commonly accepted mechanism for PH complicating lung disease) that has important therapeutic implications.

\section{Polycythemia}

Secondary polycythemia may be an adaptive response to hypoxemia. Polycythemia may lead to alteration of pulmonary vascular tone. In a study of 11 splenectomized dogs, McGrath increased the hematocrit from $43 \%$ to $65 \%$. Polycythemia alone increased PVR by $112 \%(P<0.01)$ and hypoxia alone increased PVR by $141 \%(P<0.01)$. However, combined hypoxia and Polycythemia increased PVR by $308 \%(P<0.005) .{ }^{18}$ Hasegawa and colleagues evaluated the role of polycythemia in mice. Study performed on transgenic mice with oxygen independent constitutive over expression of human erythropoietin. These mice become polycythemic at the age of 2 months with normal systemic hemodynamics compared to wild-type mice. Pulmonary artery pressure was elevated in vivo but not in vitro. This experiment provides proof to the concept that polycythemia can lead to elevated PAP. ${ }^{19}$ These studies suggest a role of polycythemia in the pathogenesis of PH. However, studies that evaluate this mechanism in COPD-related PH are needed.

\section{Inflammation}

Airway inflammation, induced by chronic cigarette smoking, may lead to pulmonary vascular changes. Cigarette smoke in rats induced proliferation of cells in pulmonary vasculature and in the airways. ${ }^{20}$ Chronic smokers with airway disease have changes in vascular structure compared to nonsmokers. Histological examination of pulmonary vasculature showed that smokers had twice as many muscularized arteries that were 0-300 $\mu \mathrm{m}$ in diameter compared to nonsmokers. In addition, there was increased fibrosis of arterial intima. $^{21}$

In COPD patients who were smokers and with normal PAP, examination of post lobectomy/pneumonectomy lungs revealed increased number of leukocytes infiltrating the arterial adventitia specifically CD8+ lymphocytes. Decreased endothelial dependent vascular relaxation in the pulmonary artery rings and increased vascular intimal thickness of the pulmonary muscular arteries noted..$^{22}$ Monocrotaline has a marked predilection for pulmonary vascular endothelium and leads to the development of $\mathrm{PH}$ with marked inflammatory infiltration of the vessels. ${ }^{23}$ This model suggests the role of toxin-mediated pulmonary vascular inflammation in PH development.

Inflammatory cytokines such as interleukin-6 (IL-6), $\mathrm{C}$-reactive protein, and tumor necrosis factor- $\alpha$ are markers of elevated PAP in COPD. ${ }^{24,25}$ Genetics may play a role and the LL phenotype of 5-HT gene is associated with higher PA pressures in hypoxemic COPD patients. ${ }^{26}$ IL-6 gene polymorphism is associated with higher serum levels of IL-6 and higher PAP in COPD. ${ }^{25}$

Various models of PH induced by toxic substances, hypoxia, and sepsis have established the role of inflammation in PH. This supports the hypothesis that inflammation plays a role in inducing vascular changes in pulmonary circulation. Further elucidation of the precise mechanism by which inflammatory cells induce vascular remodeling and $\mathrm{PH}$ remains to be determined.

\section{Shear stress}

Viscous fluids moving in a cylindrical structure create shear stress on the vessel wall. If flow remains constant, shear stress is inversely related to the inner lumen of the vessel wall radius. As the luminal diameter decreases with vasoconstriction, the shear stress in the vasculature increases. This constant stress on the vascular wall causes increased platelet degranulation, increase in inflammatory cytokine release, increase in expression of adhesion molecules, decrease in production of nitric oxide synthase and increased endothelin production. ${ }^{27,28}$ All these molecular changes can lead to alteration in pulmonary vasculature and increase PVR. Rabinovitch and colleagues altered pulmonary flow by banding single lungs in rats and exposed them to hypoxia. ${ }^{29}$ Decreased pulmonary blood flow prevented vascular changes and muscularization of peripheral pulmonary arteries of the banded lungs in hypoxic rats when compared with the contralateral lung with increased pulmonary blood flow. This experiment demonstrates that increased flow with hypoxia can augments smooth muscle content in pulmonary arteries. These studies suggest a role of shear stress in the presence of hypoxia in augmenting vascular remodeling.

\section{Endothelial dysfunction}

Lungs of COPD patients show impaired endothelium mediated vasodilatation when compared to non-COPD patients. In vitro relaxation of pulmonary artery rings obtained from patients with COPD reveal impaired relaxation to ADP suggesting that impaired endothelium-derived relaxation. ${ }^{22}$ Nitric oxide (NO) is recognized as an important endothelium-derived vasodilator playing a major role 
in maintaining vascular tone in normoxemic pulmonary vasculature. ${ }^{30}$ Smokers have decreased expression of endothelial NO synthase in pulmonary endothelium. ${ }^{31}$ Increased shear may contribute to the increase in vascular tone in the presence of reduced NO production. ${ }^{28}$ Decreased NO production due to endothelial dysfunction may have a role in $\mathrm{PH}$ in COPD. These pathological changes do have clinical significance in regards to therapy. Several agents exist currently which increase levels of NO and lead to pulmonary vasodilatation.

\section{Clinical features of pulmonary hypertension History}

Pulmonary hypertension clinically manifests as dyspnea. Patients may be asymptomatic especially in the early phase of the disease. As the disease progresses with continued elevation of PAP, the compensatory mechanisms get overwhelmed. Symptoms may vary depending upon the severity of disease. Symptoms of cor pulmonale appear with patients experiencing fatigue, dyspnea, worsening exercise limitation, chest pains, abdominal distention, and pedal edema. When this phase continues unchecked, the right ventricle fails and cardiac output begins to fall. This phase may manifest with worsening symptoms progressing to presyncope or even syncope. ${ }^{32}$ As this process further progresses it leads to shock and death.

COPD can manifest clinically as dyspnea and exercise intolerance. Until symptoms of Cor pulmonale appear, it would be difficult to identify PH clinically in these patients. As shown by Chaouat and colleagues, PH in COPD is usually mild and it would be difficult to clinically delineate from airway disease. ${ }^{12}$ During COPD exacerbations, some patients can develop pedal edema secondary to cor pulmonale with increased PAP and signs of right ventricular failure. ${ }^{33}$ Both hypoxia and hypercapnia affect the kidneys and encourage fluid retention. COPD patients during acute exacerbation may have elevated plasma renin activity and aldosterone levels that promote water and fluid retention. ${ }^{34}$ The principle cause of fluid retention in COPD patients is probably right atrial stretching leading to sympathetic nervous system firing and downstream activation of the renin-angiotensin system. Hypercapnia is thought to exacerbate these effects. This hyperaldosteronism may be reversible by the treatment of acute exacerbation. Clinically it is difficult to identify $\mathrm{PH}$ in COPD patients in the absence of right heart failure.
Table I Conditions associated with pulmonary hypertension

\begin{tabular}{|c|c|}
\hline $\begin{array}{l}\text { Heart failure } \\
\text { (Systolic/Diastolic) }\end{array}$ & $\begin{array}{l}\text { Dyspnea, exercise intolerance, angina, } \\
\text { prior myocardial infarctions, systemic } \\
\text { hypertension, valvular heart disease }\end{array}$ \\
\hline Current smoking & $\begin{array}{l}\text { Smoking cessation counseling, nicotine } \\
\text { replacement therapy }\end{array}$ \\
\hline Obstructive sleep apnea & $\begin{array}{l}\text { Snoring, excessive somnolence, } \\
\text { witnessed apneic episodes }\end{array}$ \\
\hline Autoimmune diseases & $\begin{array}{l}\text { History of skin changes, arthritis, } \\
\text { gastrointestinal problems and renal disease }\end{array}$ \\
\hline $\begin{array}{l}\text { Chronic thromboembolic } \\
\text { disease }\end{array}$ & $\begin{array}{l}\text { Prior history of pulmonary embolism, } \\
\text { deep vein thrombosis and genetic or } \\
\text { acquired hypercoagulable conditions }\end{array}$ \\
\hline Drug history & $\begin{array}{l}\text { Illicit drug abuse, prior anorexiant use } \\
\text { and herbal products }\end{array}$ \\
\hline Chronic liver disease & $\begin{array}{l}\text { History of jaundice, ascites, chronic viral } \\
\text { hepatitis and alcohol abuse. Symptoms } \\
\text { of portal hypertension including abdominal } \\
\text { distention, and gastrointestinal bleed }\end{array}$ \\
\hline HIV infection & $\begin{array}{l}\text { Sexual behavior, intravenous drug abuse } \\
\text { and needle sharing }\end{array}$ \\
\hline Congenital diseases & $\begin{array}{l}\text { History of congenital heart disease and } \\
\text { intracardiac shunts, family history of sickle } \\
\text { cell disease }\end{array}$ \\
\hline
\end{tabular}

The process of diagnosing $\mathrm{PH}$ in COPD patients should start with an evaluation geared to find clinical conditions commonly associated with elevated PAP (Table 1). Systemic hypertension is a common disease worldwide and associated with tobacco abuse. Left ventricular hypertrophy and associated diastolic dysfunction can lead to elevated pulmonary venous pressures and subsequent $\mathrm{PH} .{ }^{35}$ Smoking is a known risk factor for coronary artery disease. Post myocardial left ventricular dysfunction is common cause of systolic heart failure and subsequent PH. Presence of obstructive sleep apnea (OSA) should be investigated as a contributing cause of PH in COPD. Symptoms suggestive of OSA include snoring, witnessed apneas and daytime somnolence. ${ }^{36}$ Collagen vascular diseases are associated with $\mathrm{PH}$, and history and serologies should be undertaken to elicit autoimmune disorders. History of prior intravenous drug abuse, anorexiant use and use of natural health products should be sought. Other clinical conditions strongly associated with $\mathrm{PH}$ should be ruled out before attributing it to COPD.

\section{Physical examination}

Physical examination in $\mathrm{PH}$ would depend upon whether patient is in compensated or decompensated right heart failure. Physical examination finding in early compensated phase can be unclear. Accenuated P2 may be heard indicating 
elevated PA pressures. Midsystolic murmur caused by turbulent flow across the pulmonary artery, left parasternal heave, right-sided S4 gallop and prominent jugular wave may be seen. ${ }^{32}$ As disease progresses, hepatojugular reflex and inspiratory augmented tricuspid murmur (Caravallo's sign) may be evident. Signs of right heart failure include pulsatile liver, ascites, marked distention of jugular veins, and developing peripheral edema. ${ }^{2}$ Cardiovascular collapse due to severe cor pulmonale manifests as cold extremities and hypotension.

Many signs of classic $\mathrm{PH}$ would be altered in $\mathrm{PH}$ due to COPD. Loss of $\mathrm{X}$ descent with prominent $\mathrm{V}$ wave may suggest cor pulmonale in COPD patients. Hepatojugular reflex unmasks the murmur of tricuspid regurgitation and has $100 \%$ sensitivity and $66 \%$ specificity. Combined with Caravallo's sign the specificity rises to $93 \%{ }^{37}$ Edema may be present in COPD patients with or without cor pulmonale during acute exacerbation. ${ }^{33}$ Auscultation would be difficult in these patients secondary to change in the position of heart. Point of maximal impulse may not palpable and advanced emphysematous patients may have small and vertical heart (drop heart). ${ }^{38}$

\section{Diagnostic evaluation for pulmonary hypertension}

$\mathrm{PH}$ in COPD patients is a clinical challenge to diagnose. In the absence of right heart failure, it is difficult to identify symptoms and signs attributable to elevated PAP. The authors experience of evaluating $\mathrm{PH}$ in COPD patients is serendipitous identification of elevated PAP on echocardiogram (ECHO). The other unusual scenario is patients with airway disease with overt right heart failure. We would like to describe the changes noted in noninvasive and invasive tests in COPD patients with $\mathrm{PH}$.

\section{Electrocardiogram}

Electrocardiogram $(\mathrm{EKG})$ is a poor screening tool to diagnose PH. EKG findings suggestive of $\mathrm{PH}$ are right-axis deviation; tall $\mathrm{R}$ wave and small $\mathrm{S}$ wave with $\mathrm{R} / \mathrm{S}$ ratio $>1$ in lead $\mathrm{V} 1$, qR complex in lead V1, rSR' pattern in lead V1, large $\mathrm{S}$ wave and small $\mathrm{R}$ wave with $\mathrm{R} / \mathrm{S}$ ratio $<1$ in lead $\mathrm{V} 5$ or $\mathrm{V} 6$; or S1, S2, S3 pattern. ST-T segment wave depression and inversion may be present in the right precordial leads. Right atrial enlargement manifests as a tall $\mathrm{P}$ wave $(>2.5 \mathrm{~mm})$ in leads II, III, and aVF and frontal P-axis of $75^{\circ} .32$

Study performed in a cohort of patients with pulmonary arterial hypertension (PAH) and PAH secondary to collagen vascular diseases documented abnormal EKG findings in $87 \%$ of these patients. ${ }^{39}$ No data exists regarding the predictive values and prognostic significance of EKG changes in COPD patients with PH. EKG may be useful in evaluating and excluding other conditions such as ischemic cardiomyopathy and left ventricular hypertrophy.

\section{Radiological studies Chest radiograph}

Chest X-ray may reveal findings suggestive of $\mathrm{PH}$. A radiological index obtained by measuring the horizontal distances from the midline to the first divisions of the right and left pulmonary arteries, and dividing the sum of these distances by the maximum transverse diameter of the thorax can predict $\mathrm{PH}$. An abnormal index was suggestive of $\mathrm{PH}$. However, this did not correlate with disease severity. ${ }^{40}$ This index may not be accurate in COPD patients in the presence of hyperinflation. Enlarged main and hilar pulmonary arterial shadows, with concomitant attenuation of peripheral pulmonary vascular markings (pruning) is suggestive of PH. Right ventricular enlargement is seen on lateral films as impingement of the anteriorly situated right ventricular silhouette into the retrosternal clear space. ${ }^{2}$ The usefulness of these signs in patients with COPD is unknown.

\section{Echocardiogram}

Echocardiogram (ECHO) is a commonly used screening tool for evaluating PH. It is a simple noninvasive test that can provide details of biventricular function and anatomy. Doppler ECHO can be used to calculate the right ventricle systolic pressure (RVSP) if tricuspid regurgitation jet is noted. Presence of tricuspid jet is crucial to this measurement. Pulmonary artery pressure approximately equals to right ventricular systolic pressure in the absence of pulmonary artery outflow obstruction or stenosis. The right ventricular pressure (RVP) is approximated by the modified Bernoulli equation as $4 v^{2}$, in which $v$ is the velocity of the tricuspid jet in meters per second. RVSP obtained by adding right atrial pressure (RAP) to the RVP. ${ }^{32}$ RAP estimate is based on either the height of jugular venous pulse or echocardiographic features of inferior vena cava:

$$
\mathrm{RVSP}=4 \mathrm{v}^{2}+\mathrm{RAP}
$$

In one study, RVSP could not be estimated in $34 \%$ of COPD patients. ${ }^{41}$ This was due to poor quality signal, inadequate tricuspid regurgitation (TR) or absence of Doppler-detected TR. Increased intrathoracic gas, expansion of the thoracic cage, and alterations in the position of the heart can adversely affect detection and measurement of 
TR jet velocity. In a large series of 374 patients with advanced lung disease (COPD 68\%), significant correlation was seen between PAP estimated by Doppler ECHO and RHC. ${ }^{42}$ However, the study revealed several limitations of the ECHO in this population. Estimation of PAP was possible in $44 \%$ of patients with advanced lung disease similar to the previous study. ${ }^{41}$ Doppler ECHO-estimated systolic PAP was accurate (within $10 \mathrm{~mm} \mathrm{Hg}$ of RHC measurement) in only $48 \%$ of patients. However, the accuracy of Doppler ECHO was higher in patients with obstructive lung disease than in ILD or pulmonary vascular disease. The likelihood of estimating systolic PAP was lower in patients with marked air trapping define as residual volume $>150 \%(40 \%$ versus $56 \% ; P=0.007) .{ }^{42}$ In a study by Himelman and colleagues, the detection rate of TR jet could be improved from $56 \%$ to $92 \%(P<0.001)$ by the use of agitated saline contrast. ${ }^{43}$ These studies show low sensitivity of ECHO in estimating PAP in COPD patients and agitated saline contrast may improve the detection rate. Fisher and colleagues compared echocardiographic estimate of PAP with RHC. ECHO was performed within one hour post-RHC and was inaccurate ( $>10 \mathrm{~mm} \mathrm{Hg}$ variability) in $48 \%$ of cases. Overestimation and underestimation were noted with similar frequency and the magnitude of underestimation was more. This study shows the inadequacy of ECHO in both identifying and quantifying PAP. ${ }^{44}$

ECHO can provide reliable data on abnormal anatomy of left heart and functional parameters which potentially can lead to elevated PAP. ${ }^{45}$ Intra cardiac shunts and valvular abnormalities can be recognized. ECHO derived data on pericardial effusion, right atrial enlargement and degree of septal displacement in diastole can predict mortality in $\mathrm{PH}^{46}$ These markers indicated right ventricular failure in $\mathrm{PAH}$ patients. The applicability of these markers in COPD-related $\mathrm{PH}$ is unknown.

\section{Chest computed tomography}

Computerized tomography (CT) of the chest is an emerging diagnostic modality in $\mathrm{PH}$ evaluation. An advance in $\mathrm{CT}$ technology has led to improved imaging of heart and pulmonary vasculature. Contiguous $10 \mathrm{~mm} \mathrm{CT}$ sections obtained with a 15 second breath-holding spiral technique were obtained in normal and proven PH patients (mean PAP $>20 \mathrm{~mm} \mathrm{Hg}$ ). Main PA diameter of $3.32 \mathrm{~cm}$ had $58 \%$ sensitivity and $95 \%$ specificity for presence of PAH. ${ }^{47}$ The mean PAP used in this study was lower than the accepted definition of PH. Multidetector row $\mathrm{CT}$ with three-dimensional volume rendering can elucidate pulmonary vein anatomy in the thorax.$^{48}$ This technology defines the anatomic details of main pulmonary veins draining into the left atrium. Abnormalities in the pulmonary venous drainage can prompt evaluation for structural anomalies causing $\mathrm{PH} .{ }^{49}$ Contracter and colleagues evaluated the role of helical $\mathrm{CT}$ chest in diagnosing right ventricular dysfunction after acute pulmonary embolism (PE). Right ventricular dilation and deviation of interventricular septum towards left ventricle were the criteria used to define right ventricle dysfunction. The sensitivity of $\mathrm{CT}$ chest for detecting right ventricle dysfunction was $78 \%$ and specificity $100 \%$, with a positive predictive value of $100 \% .{ }^{50}$ Although, this was a retrospective study of 25 patients, chest CT may provide an option for evaluating right ventricle dysfunction in COPD patients especially when ECHO Doppler proves inadequate.

\section{Magnetic resonance imaging}

Cardiac magnetic resonance imaging (MRI) can provide anatomical details of the right ventricle and pulmonary vasculature. It can calculate multiple right ventricular parameters like right ventricular end systolic volume, right ventricular end diastolic volume, right ventricular stroke volume, and right ventricular ejection fraction. Right ventricular diastolic dysfunction appears to be prevalent in $\mathrm{PH}$ patients. Isovolumic relaxation time, normalized right ventricular early peak filling rate (E), atrium-induced peak filling rate (A), and E/A ratio can be obtained to evaluate right ventricular diastolic dysfunction. ${ }^{51}$ Gan and colleagues showed that increased isovolumetric relaxation time and decreased E/A ratio were indicative of right ventricular diastolic dysfunction. ${ }^{52}$ MRA with gadolinium was shown to be $77 \%$ sensitive and $98 \%$ specific in detection of PE in a prospective study of 141 patients with suspected PE..$^{53}$

COPD-related PH is generally mild/moderate and may not be associated with right ventricle (right ventricular) dysfunction until later in the disease course. right ventricule is chronically pressure overloaded in PH leading to (initial) hypertrophy as opposed to acutely overloaded in acute embolism which leads to dilation and bowing of the septum. Therefore the CT technique may not be applicable as an early detection or screening tool. MRI might be a more sensitive technique for detection of $\mathrm{PH}$ associated markers like right ventricular diastolic dysfunction, increased right ventricular mass and PVR. Further research needs to be done to determine the utility of these techniques in COPD-related PH.

\section{Right heart catheterization}

Right heart catheterization is the gold standard to diagnose $\mathrm{PH}$. Heart catheterization provides accurate measurement of mean 
pulmonary artery pressure to diagnose $\mathrm{PH}$ and pulmonary wedge pressure to determine the presence of pulmonary venous hypertension. ${ }^{32}$ Pulmonary vascular reactivity is assessed during the RHC and presence of reactivity has important therapeutic and prognostic implications in PAH. ${ }^{54}$ The major drawback is the invasive nature of the procedure. No studies have evaluated its role in COPD. The clinical conundrum would be selection of patients. For obvious reasons all patients with COPD cannot be subjected to heart catheterization. The optimal strategy would be to perform it on patients exhibiting signs and symptoms of right heart dysfunction. The authors feel its major role is to find elevated wedge pressures. This would identify left ventricular dysfunction and appropriate measures can be undertaken. Management of isolated precapillary elevated pulmonary pressure in COPD is unknown currently. The treatment strategy and benefits of treatment are unanswered questions.

\section{Serological markers}

Elevated serum brain-type natriuretic peptide (BNP) is a marker of myocardial stretch. Elevation in plasma BNP with exercise in COPD patients with normal right ventricles at rest suggests exercise induced $\mathrm{PH} .{ }^{55}$ Plasma BNP levels are higher in COPD patients compared to normal subjects. Elevated plasma BNP correlates with pulmonary artery systolic pressure. ${ }^{56}$ BNP cutoff value of $36 \mathrm{pg} / \mathrm{ml}$ has a sensitivity and specificity of $75 \%$ and $89 \%$ in diagnosing cor pulmonale in COPD. ${ }^{57}$ All the above studies are single center investigations with small number of patients. The caveat in these studies is the low BNP value and hence poor specificity due to potential overlap with normal subjects. Large studies need to be conducted to validate these findings. The use of BNP can identify patients with subclinical PH. Further research needed to understand the clinical implication of identifying pre-clinical PH in COPD.

\section{Diagnostic strategy}

COPD confounds the classical manifestations of PH. Usual signs and symptoms of PH may be absent. Signs of right heart failure should trigger an evaluation for $\mathrm{PH}$ (Figure 2). ECHO is the initial screening tool of choice for PH. This simple noninvasive test can provide estimate of right ventricular systolic and RAPs. The utility of diagnosing sub-clinical $\mathrm{PH}$ is currently unknown. The authors feel that identification of elevated PAP in COPD patients by an ECHO should be followed by a RHC for confirmation (Figure 2) and to exclude alternative etiologies as stated in Table 1.
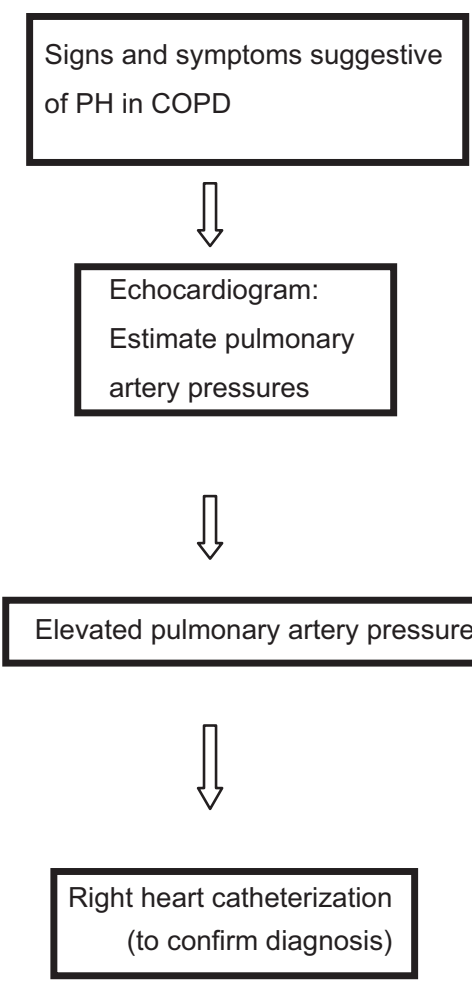

Figure 2 Diagnostic approach to a COPD patient with suspected $\mathrm{PH}$.

Abbreviations: COPD, chronic obstructive pulmonary disease; $\mathrm{PH}$, pulmonary hypertension.
Diagnostic studies to pursue alternate diagnosis (Table 1) 


\section{Therapeutics}

\section{Avoidance of airway irritants}

Tobacco smoke is the most common cause of COPD. Multiple studies have reported improvement in functional markers, symptoms, morbidity and mortality in COPD with smoking cessation. ${ }^{58,59}$ Smoking cessation is an integral part of COPD management as stated by multiple health organizations. All smokers irrespective of symptoms should be counseled on the deleterious effects of smoking and cessation strategies. Even though, no studies exist evaluating the effect of smoking cessation on $\mathrm{PH}$, authors strongly recommend smoking cessation for COPD patients with $\mathrm{PH}$ due to the obvious clinical benefits. Recent epidemiological studies have shown the role of biofuel smoke in causation of COPD. An autopsy study has revealed pathological changes similar to tobacco induced lung disease. ${ }^{15}$ No evidence is available yet evaluating the role of avoidance in biofuel induced lung disease. If evidence from smoking studies is considered, then avoidance of biofuel smoke may have similar benefits.

\section{Oxygen therapy}

Oxygen therapy is a cornerstone of COPD management in patients with hypoxemia. Two seminal trails have shown the survival benefit with long-term oxygen therapy. The Nocturnal Oxygen Treatment Trial (NOTT) included subjects with arterial $\mathrm{PaO}_{2} 55 \mathrm{~mm} \mathrm{Hg}$ or less or arterial $\mathrm{PaO}_{2} 59 \mathrm{~mm} \mathrm{Hg}$ or less with coexisting peripheral edema, hematocrit at least 55\% or P pulmonale on EKG. The trial demonstrated a survival benefit of continuous supplemental oxygen therapy over nocturnal oxygen use. The average duration of treatment was 19.3 months. PVR and hematocrit reduced more in subjects that were on continuous oxygen therapy ${ }^{60}$
The Medical Research Council (MRC) trial included patients with severe COPD, $\mathrm{PaO}_{2}$ between 40 and $60 \mathrm{~mm} \mathrm{Hg}$, hypercapnia and history of congestive heart failure ${ }^{61}$ Subjects received either oxygen for at least $15 \mathrm{~h} /$ day, usually at $2 \mathrm{~L}$ per minute, or no oxygen. The follow-up period was five years. A survival benefit with the use of continuous oxygen over no oxygen noted after 500 days. In this study, subjects on room air showed increase in PAP while those on oxygen therapy showed no such increase. Both trials were not methodologically designed to determine the survival benefit of hemodynamic changes noted with oxygen therapy.

Hypoxemia plays a significant role in $\mathrm{PH}$ associated with COPD. Although inhaled NO and 100\% oxygen decreased PAP in such patients, pulmonary gas exchange worsened due to ventilation-perfusion imbalance. ${ }^{62}$ Hemodynamic evaluation of COPD patients showed no correlation between right ventricular ejection fraction and PAP. A weak correlation between RVEF and PVR was noted providing a suggestion that as PVR increased the right ventricular function deteriorated. ${ }^{63}$ Low flow oxygen therapy improved RVEF during exercise in COPD patients when compared to room air. ${ }^{64}$ This study shows that oxygen therapy can improve right ventricular function during exercise. In another study, COPD patients received $28 \%$ oxygen for 24 hours and mean PAP response was measured. Fall in mean PAP of $\geq 5 \mathrm{~mm} \mathrm{Hg}$ was considered a significant response to oxygen and predicted improved survival. ${ }^{65}$

Oswald-Mammosser and colleagues evaluated the prognostic significance of $\mathrm{PH}$ in hypoxic COPD patients requiring supplemental oxygen. ${ }^{66}$ The five-year survival rate was of $62.2 \%$ in patients with $\mathrm{PAP}<25 \mathrm{~mm} \mathrm{Hg}$ compared to $36.3 \%$ seen in subjects with PAP $>25 \mathrm{~mm} \mathrm{Hg}$

Table 2 Summary of few studies to treat COPD-related PH

\begin{tabular}{|c|c|c|c|}
\hline Study & Agent & Result & Comment \\
\hline $\begin{array}{l}\text { Nocturnal Oxygen Treatment } \\
\text { Trial (NOTT) }{ }^{60}\end{array}$ & Oxygen & $\begin{array}{l}\text { Decrease in PVR with continuous } \\
\text { oxygen supplementation }\end{array}$ & $\begin{array}{l}\text { Survival benefit with continuous oxygen use } \\
\text { with reduction in PVR and hematocrit }\end{array}$ \\
\hline $\begin{array}{l}\text { Medical Research Council } \\
(\mathrm{MRC}) \text { trial }^{61}\end{array}$ & Oxygen & $\begin{array}{l}\text { PAP stable with } \mathrm{O}_{2} \text { supplementation } \\
\text { compared to increase noted with } \\
\text { room air }\end{array}$ & Survival benefit after 500 days of oxygen use \\
\hline Zielinski J et al ${ }^{67}$ & Oxygen & $\begin{array}{l}\text { Initial fall and subsequent stabilization } \\
\text { of PAP with long term oxygen therapy }\end{array}$ & $\begin{array}{l}\text { Worsening airway disease in presence } \\
\text { of long term oxygen therapy }\end{array}$ \\
\hline Vonbank et $\mathrm{al}^{69}$ & Inhaled NO + oxygen & $\begin{array}{l}\text { Improved PAP and PVR after } \\
\text { three months of pulsed NO inhalation }\end{array}$ & $\begin{array}{l}\text { Short study duration. Needs validation } \\
\text { in long term studies }\end{array}$ \\
\hline Alp et $\mathrm{al}^{75}$ & Sildenafil & $\begin{array}{l}\text { Improvement in PAP, PVR and 6MWT } \\
\text { acutely and after three months }\end{array}$ & $\begin{array}{l}\text { Small subject population with six initially and } \\
\text { five after three months follow-up }\end{array}$ \\
\hline Valerio $\mathrm{G}$ et $\mathrm{al}^{78}$ & Bosentan & $\begin{array}{l}\text { Improvement in PAP, PVR, and 6MWD } \\
\text { after } 18 \text { months }\end{array}$ & Small subject population of 16 patients \\
\hline
\end{tabular}


$(P<0.001) . \mathrm{PaO}_{2}$ levels were not significantly different in the two groups. In a study by Zielinski and colleagues, long term oxygen therapy minimally improved mean PAP in the first two years, however mean PAP returned to baseline and remained unchanged despite worsening hypoxemia in this cohort of hypoxemic COPD patients. ${ }^{67}$ These studies provide support for using oxygen in hypoxemic COPD patients that may confer a survival benefit to these patients.

\section{Vasodilator therapy}

Multiple pharmacological agents have pulmonary vasodilatory effects. Studies in PAH have shown the effectiveness of these agents on pulmonary hemodynamics, however their utility in COPD-related PH remains to be determined.

\section{Nitric oxide}

Nitric oxide is an important endothelial derived pulmonary vasodilator that plays an important role in hypoxia-induced pulmonary vasoconstriction. Biochemically, it induces vasodilatation by increasing cyclic guanosine monophosphate (cGMP) levels in vascular smooth muscles. ${ }^{30}$ Administration of inhaled NO in COPD can lead to worsening of gas exchange due to impaired ventilation-perfusion matching. ${ }^{62}$ NO with oxygen therapy can lead to pulmonary vasodilatation without the deleterious effect on gas exchange.

NO administered by inhalation through a nasal canula at a dose of 25 parts per million for 24 hours with oxygen, reduced PVR without significant change in mean PAP. ${ }^{68}$ Breathing NO for 24 hours resulted in a significant increase in cardiac output. All subjects were on home oxygen and the mean PAP prior to intervention was 26.1 and remained unchanged post intervention A randomized prospective trial was conducted in hypoxic COPD patients with $\mathrm{PH}$ (mean PAP $>25 \mathrm{~mm} \mathrm{Hg}$ ) with pulsed inhaled NO plus oxygen over three months. ${ }^{69} \mathrm{NO}$ plus oxygen decreased PVR, mean PAP, and increased cardiac output without worsening oxygenation. This study shows the improvement in pulmonary hemodynamics with inhaled NO. Baigori and colleagues.explored the role of inhaled NO on pulmonary hemodynamics in acute COPD exacerbation. Twelve mechanically ventilated patients with acute COPD exacerbation were administered inhaled NO (20 parts per million (ppm) for 20 minutes. ${ }^{70}$ Mean PAP fell, but arterial oxygenation, RVEF, and cardiac output remained unchanged. Based on the current available studies we know that inhaled NO does lead to pulmonary hemodynamic benefits in COPD. However, the translation of this hemodynamic improvement into clinical benefit is unexplored in COPD-related $\mathrm{PH}$ population. The major limitation of this drug is the difficulty in delivery, maintaining dosage, and patient discomfort due to mode of delivery.

\section{Prostacyclin}

Prostacyclin is an endogenously produced pulmonary vasodilator. In a study by Archer and colleagues, prostacyclin infusion for 48 hours in mechanically ventilated COPD patients with $\mathrm{PH}$ and acute respiratory failure showed no significant benefit. ${ }^{71}$ PVR and SVR fell initially but response was unsustained despite optimization of prostacyclin dosage. $\mathrm{PaO}_{2}$ dropped in patients receiving prostacyclin infusion compared to placebo group despite comparable inspired oxygen concentration. Lack of efficacy of prostacyclin can be attributable to multiple reasons. One could be ventilationperfusion mismatch and worsening oxygenation in patients with parenchymal lung disease. Prostacyclin can increase intrapulmonary shunting causing lower systemic oxygen saturation. However, increased right ventricular output by prostacyclin may counterbalance the increased shunting. Further studies are required to address the balance of these counter effects of prostacyclin.

A newer compound, cicletanine enhances endogenous prostacylin production. Saadjain and colleagues administered cicletanine (50 mg daily) for 12 months to COPD patients with $\mathrm{PH} .{ }^{72}$ In this small study, cicletanine resulted in a reduction of mean PAP and PVR after three and 12 months of treatment. There was a small but a nonsignificant reduction of $\mathrm{PaO}_{2}$. Further studies are needed to evaluate the role of this agent in PH due to COPD. Currently a large phase II clinical trial is under way evaluating the role of Cicletanine in PAH (see http://www.clinicaltrials.gov/). This study might provide further information about the effects on cicletanine on pulmonary vascular hemodynamics.

\section{Phosphodiesterase inhibitors}

Phosphodiesterase (PDE) inactivates cGMP, the second messenger of the prostacyclin pathway. The majority of PDE present in the lungs is PDE5. PDE5-inhibition blocks the degradation of cGMP and enhances the vasodilatory action of cGMP.

Sildenafil is the prototype drug in this category. In a heterogeneous group of secondary $\mathrm{PH}$ patients (patients with chronic thromboembolic disease, $\mathrm{PH}$ due to valvular abnormalities and COPD), response to sildenafil was studied. Sildenafil administration resulted in improved six-minute walk distance over long-term follow-up (range 12-51 months). ${ }^{73}$ Changes in PVR were variable and ECHO 
showed improvement in right ventricular function. In patients with PH and severe COPD and idiopathic pulmonary fibrosis, $50 \mathrm{mg}$ sildenafil three times daily resulted in subjective improvement in all subjects. ${ }^{74}$ In a study evaluating the role of sildenafil in six patients, the PVR index dropped. Cardiac output and cardiac index showed no significant improvement. ${ }^{75}$ One time $50 \mathrm{mg}$ dose of intravenous sildenafil reduced PAP and PVR and after three months of oral therapy, six-minute walk significantly improved. ${ }^{76}$ Sildenafil decreased the rise in mean PAP with exercise irrespective of baseline PAP in patients with COPD. Few available studies have shown that sildenafil improves hemodynamics and functional markers in this patient population. Confirmation of these results in larger studies in COPD-related $\mathrm{PH}$ is pending.

\section{Endothelin receptor antagonist}

Endothelin-1 is a powerful vasoconstrictive agent produced by vascular endothelium and plays a major role in vascular homeostasis. Blockage of endothelin receptor leads to pulmonary vasodilation. Studies have shown its efficacy in PAH. Administration of endothelin receptor antagonists such as Bosentan in PH secondary to COPD has yielded conflicting results. Bosentan administration in COPD-related $\mathrm{PH}$ patients for 12 weeks, resulted in worsening hypoxemia with no improvement in six-minute walk distance. ${ }^{77}$ Another study by Valerio and colleagues showed that Bosentan administration for 18 months resulted in an improvement in six-minute walk distance, PAP, and PVR ${ }^{78}$ These conflicting results need to be reconciled in a large randomized clinical trial that is currently underway. However, given the lack of convincing evidence, the use of Bosentan in COPD-related $\mathrm{PH}$ is not recommended.

\section{Conclusion}

COPD-related PH is usually mild. Small subset of patients demonstrates significant $\mathrm{PH}$ and the clinical significance is limited to poor prognosis. Initial goal of management is to identify alternate remediable causes. There is no current therapy targeting $\mathrm{PH}$ in COPD. Smoking cessation and oxygen therapy remain the only proven therapies for COPD and should be recommended to all COPD patients. Anecdotal reports suggest utility of PDE5-inhibitor and prostacyclin in treatment of $\mathrm{PH}$ associated with COPD. Targeted agents and strategies are still to be discovered.

\section{Disclosures}

The authors report no conflicts of interest in this work.

\section{References}

1. Simonneau G, Galie N, Rubin LJ, et al. Clinical classification of pulmonary hypertension. J Am Coll Cardiol. 2004;43(12 Suppl ):5S-12S.

2. Rich S, Dantzker DR, Ayres SM, et al. Primary pulmonary hypertension. A national prospective study. Ann Intern Med. 1987;107(2): 216-223.

3. McLaughlin VV, Archer SL, Badesch DB, et al. ACCF/AHA 2009 expert consensus document on pulmonary hypertension: a report of the American College of Cardiology Foundation Task Force on Expert Consensus Documents and the American Heart Association: developed in collaboration with the American College of Chest Physicians, American Thoracic Society, Inc., and the Pulmonary Hypertension Association. Circulation. 2009;119(16):2250-2294.

4. Orozco-Levi M, Garcia-Aymerich J, Villar J, et al. Wood smoke exposure and risk of chronic obstructive pulmonary disease. Eur Respir J. 2006;27:542-546

5. Global Initiative for Chronic Obstructive Lung Disease. Pocket Guide to COPD Diagnosis, Management, and Prevention. A Guide for Health Care Professionals. Global Initiative for Chronic Obstructive Lung Disease; 2008.

6. US Department of Health and Human services, National Institutes of Health, National Heart, Lung and Blood Institute. Data Fact Sheet: Chronic Obstructive Pulmonary Disease. NIH Publication Number 03-5229 March 2003. Available from: http://www.bipac.net/cqrc_test/ NHLBI_COPD_Fact Sheet.pdf. Accessed on August 22, 2009.

7. Buist AS, McBurnie MA, Vollmer WM, et al. International variation in the prevalence of COPD (the BOLD Study): a population-based prevalence study. Lancet. 2007;370(9589):741-750.

8. Menezes AM, Perez-Padilla R, Jardim JR, et al. Chronic obstructive pulmonary disease in five Latin American cities (the PLATINO study): a prevalence study. Lancet. 2005;366(9500):1875-1881.

9. Naeije R. Pulmonary hypertension and right heart failure in chronic obstructive pulmonary disease. Proc Am Thorac Soc. 2005;2(1):20-22.

10. Oswald-Mammosser M, Apprill M, Bachez P, Ehrhart M, Weitzenblum E. Pulmonary hemodynamics in chronic obstructive pulmonary disease of the emphysematous type. Respiration. 1991; 58(5-6):304-310.

11. Scharf SM, Iqbal M, Keller C, Criner G, Lee S, Fessler HE. Hemodynamic characterization of patients with severe emphysema. Am J Respir Crit Care Med. 2002;166(3):314-322.

12. Chaouat A, Bugnet AS, Kadaoui N, et al. Severe pulmonary hypertension and chronic obstructive pulmonary disease. Am J Respir Crit Care Med. 2005;172(2):189-194.

13. Thabut G, Dauriat G, Stern G, et al. Pulmonary hemodynamics in advanced COPD candidates for lung volume reduction surgery or lung transplantation. Chest. 2005;127(5):1531-1536.

14. Kessler R, Faller M, Weitzenblum E, et al. "Natural history" of pulmonary hypertension in a series of 131 patients with chronic obstructive lung disease. Am J Respir Crit Care Med. 2001;164(2):219-224.

15. Moran-Mendoza O, Pérez-Padilla JR, Salazar-Flores M, et al. Wood smoke-associated lung disease: a clinical, functional, radiological and pathological description. Int J Tuberc Lung Dis. 2008;12(9):1092-1098.

16. Barbera JA, Riverola A, Roca J, et al. Pulmonary vascular abnormalities and ventilation-perfusion relationships in mild chronic obstructive pulmonary disease. Am J Respir Crit Care Med. 1994;149(2 Pt 1):423-429.

17. McFarlane PA, Gardaz JP, Sykes MK. $\mathrm{CO}_{2}$ and mechanical factors reduce blood flow in a collapsed lung lobe. JAppl Physiol. 1984;57(3): 739-743.

18. McGrath RL, Weil JV. Adverse effects of normovolemic polycythemia and hypoxia on hemodynamics in the dog. Circ Res. 1978;43(5):793-798.

19. Hasegawa J, Wagner KF, Karp D, et al. Altered pulmonary vascular reactivity in mice with excessive erythrocytosis. Am J Respir Crit Care Med. 2004;169(7):829-835.

20. Sekhon HS, Wright JL, Churg A. Cigarette smoke causes rapid cell proliferation in small airways and associated pulmonary arteries. Am J Physiol. 1994;267(5 Pt 1):L557-L563. 
21. Hale KA, Ewing SL, Gosnell BA, Niewoehner DE. Lung disease in long-term cigarette smokers with and without chronic air-flow obstruction. Am Rev Respir Dis. 1984;130(5):716-721.

22. Peinado VI, Barbera JA, Ramirez J, et al. Endothelial dysfunction in pulmonary arteries of patients with mild COPD. Am J Physiol. 1998; 274(6 Pt 1):L908-L913.

23. Voelkel NF, Tuder RM, Bridges J, Arend WP. Interleukin-1 receptor antagonist treatment reduces pulmonary hypertension generated in rats by monocrotaline. Am J Respir Cell Mol Biol. 1994;11(6):664-675.

24. Joppa P, Petrasova D, Stancak B, Tkacova R. Systemic inflammation in patients with COPD and pulmonary hypertension. Chest. 2006;130(2):326-333.

25. Chaouat A, Savale L, Chouaid C, et al. Role for interleukin-6 in COPD-related pulmonary hypertension. Chest. 2009;Apr 6. [Epub ahead of print].

26. Eddahibi S, Chaouat A, Morrell N, et al. Polymorphism of the serotonin transporter gene and pulmonary hypertension in chronic obstructive pulmonary disease. Circulation. 2003;108(15):1839-1844.

27. Nomura S, Tandon NN, Nakamura T, Cone J, Fukuhara S, Kambayashi J. High-shear-stress-induced activation of platelets and microparticles enhances expression of cell adhesion molecules in THP-1 and endothelial cells. Atherosclerosis. 2001;158(2):277-287.

28. Zhu ZG, Li HH, Zhang BR. Expression of endothelin-1 and constitutional nitric oxide synthase messenger RNA in saphenous vein endothelial cells exposed to arterial flow shear stress. Ann Thorac Surg. 1997;64(5):1333-1338.

29. Rabinovitch M, Konstam MA, Gamble WJ, et al. Changes in pulmonary blood flow affect vascular response to chronic hypoxia in rats. Circ Res. 1983;52(4):432-441.

30. Stamler JS, Loh E, Roddy MA, Currie KE, Creager MA. Nitric oxide regulates basal systemic and pulmonary vascular resistance in healthy humans. Circulation. 1994;89(5):2035-2040.

31. Barbera JA, Peinado VI, Santos S, Ramirez J, Roca J, Rodriguez-Roisin R. Reduced expression of endothelial nitric oxide synthase in pulmonary arteries of smokers. Am J Respir Crit Care Med. 2001;164(4):709-713.

32. McGoon M, Gutterman D, Steen V, et al. Screening, early detection, and diagnosis of pulmonary arterial hypertension: ACCP evidence-based clinical practice guidelines. Chest. 2004;126(1 Suppl):14S-34S.

33. Weitzenblum E, Apprill M, Oswald M, Chaouat A, Imbs JL. Pulmonary hemodynamics in patients with chronic obstructive pulmonary disease before and during an episode of peripheral edema. Chest. 1994;105(5):1377-1382.

34. Farber MO, Weinberger MH, Robertson GL, Fineberg NS, Manfredi F. Hormonal abnormalities affecting sodium and water balance in acute respiratory failure due to chronic obstructive lung disease. Chest. 1984;85(1):49-54.

35. Pedrinelli R, Dell'Omo G, Talini E, Canale ML, Di Bello V. Systemic hypertension and the right-sided cardiovascular system: a review of the available evidence. J Cardiovasc Med (Hagerstown). 2009;10(2): $115-121$.

36. Sajkov D, Doug McEvoy R. Obstructive sleep apnea and pulmonary hypertension. Prog Cardiovasc Dis. 2009;51(5):363-370.

37. Maisel AS, Atwood JE, Goldberger AL. Hepatojugular reflux: useful in the bedside diagnosis of tricuspid regurgitation. Ann Intern Med. 1984;101(6):781-782.

38. Tokuda Y, Miyagi S. Physical diagnosis of chronic obstructive pulmonary disease. Intern Med. 2007;46(23):1885-1891.

39. Ahearn GS, Tapson VF, Rebeiz A, Greenfield JC Jr. Electrocardiography to define clinical status in primary pulmonary hypertension and pulmonary arterial hypertension secondary to collagen vascular disease. Chest. 2002;122(2):524-527.

40. Lupi E, Dumont C, Tejada VM, Horwitz S, Galland F. A radiologic index of pulmonary arterial hypertension. Chest. 1975;68(1):28-31.

41. Laaban JP, Diebold B, Zelinski R, Lafay M, Raffoul H, Rochemaure J. Noninvasive estimation of systolic pulmonary artery pressure using Doppler echocardiography in patients with chronic obstructive pulmonary disease. Chest. 1989;96(6):1258-1262.
42. Arcasoy SM, Christie JD, Ferrari VA, et al. Echocardiographic assessment of pulmonary hypertension in patients with advanced lung disease. Am J Respir Crit Care Med. 2003;167(5):735-740.

43. Himelman RB, Stulbarg M, Kircher B, et al. Noninvasive evaluation of pulmonary artery pressure during exercise by saline-enhanced Doppler echocardiography in chronic pulmonary disease. Circulation. 1989;79(4):863-871.

44. Fisher M, Forfia P, Chamera E, et al. Accuracy of Doppler echocardiography in the hemodynamic assessment of pulmonary hypertension. Am J Respir Crit Care Med. 2009;179:615-621.

45. Ommen SR, Nishimura RA. A clinical approach to the assessment of left ventricular diastolic function by Doppler echocardiography: update 2003. Heart. 2003;89(Suppl 3):iii18-iii23.

46. Raymond RJ, Hinderliter AL, Willis PW, et al. Echocardiographic predictors of adverse outcomes in primary pulmonary hypertension. J Am Coll Cardiol. 2002;39(7):1214-1219.

47. Edwards PD, Bull RK, Coulden R: CT measurement of main pulmonary artery diameter. Br J Radiol. 1998;71(850):1018-1020.

48. Lawler LP, Corl FM, Fishman EK. Multi-detector row and volumerendered $\mathrm{CT}$ of the normal and accessory flow pathways of the thoracic systemic and pulmonary veins. Radiographics. 2002;22 Spec No: S45-S60.

49. Ley S, Kreitner KF, Fink C, Heussel CP, Borst MM, Kauczor HU. Assessment of pulmonary hypertension by $\mathrm{CT}$ and MR imaging. Eur Radiol. 2004;14(3):359-368.

50. Contractor S, Maldjian PD, Sharma VK, Gor DM. Role of helical CT in detecting right ventricular dysfunction secondary to acute pulmonary embolism. J Comput Assist Tomogr. 2002;26(4):587-591.

51. Tandri H, Daya SK, Nasir K, et al. Normal reference values for the adult right ventricle by magnetic resonance imaging. Am J Cardiol. 2006;98(12):1660-1664.

52. Gan CT, Holverda S, Marcus JT, et al. Right ventricular diastolic dysfunction and the acute effects of sildenafil in pulmonary hypertension patients. Chest. 2007;132(1):11-17.

53. Oudkerk M, van Beek EJ, Wielopolski P, et al. Comparison of contrastenhanced magnetic resonance angiography and conventional pulmonary angiography for the diagnosis of pulmonary embolism: a prospective study. Lancet. 2002;359(9318):1643-1647.

54. Sitbon O, Humbert M, Jais X, et al. Long-term response to calcium channel blockers in idiopathic pulmonary arterial hypertension. Circulation. 2005;111(23):3105-3111.

55. Gemici G, Erdim R, Celiker A, et al. B-type natriuretic peptide levels in patients with COPD and normal right ventricular function. Adv Ther. 2008;25(7):674-680.

56. Inoue $\mathrm{Y}$, Kawayama $\mathrm{T}$, Iwanaga $\mathrm{T}$, et al. high plasma brain natriuretic peptide levels in stable COPD without pulmonary hypertension or cor pulmonale. Intern Med. 2009;48(7):503-512.

57. Bozkanat E, Tozkoparan E, Baysan O, Deniz O, Ciftci F, Yokusoglu M. The significance of elevated brain natriuretic peptide levels in chronic obstructive pulmonary disease. $J$ Int Med Res. 2005;33(5):537-544.

58. Willemse BW, Postma DS, Timens W, ten Hacken NH. The impact of smoking cessation on respiratory symptoms, lung function, airway hyperresponsiveness and inflammation. Eur Respir J. 2004;23: 464-476.

59. Godtfredsen N, Lam T, Hansel T. COPD-related morbidity and mortality after smoking cessation: status of the evidence. Eur Respir J. 2008;32:844-853.

60. Continuous or nocturnal oxygen therapy in hypoxemic chronic obstructive lung disease: a clinical trial. Nocturnal Oxygen Therapy Trial Group. Ann Intern Med. 1980;93(3):391-398.

61. Long term domiciliary oxygen therapy in chronic hypoxic cor pulmonale complicating chronic bronchitis and emphysema. Report of the Medical Research Council Working Party. Lancet. 1981;1(8222):681-686.

62. Barbera JA, Roger N, Roca J, Rovira I, Higenbottam TW, RodriguezRoisin R. Worsening of pulmonary gas exchange with nitric oxide inhalation in chronic obstructive pulmonary disease. Lancet. 1996; 347(8999):436-440. 
63. Biernacki W, Flenley DC, Muir AL, MacNee W. Pulmonary hypertension and right ventricular function in patients with COPD. Chest. 1988;94(6):1169-1175.

64. Olvey SK, Reduto LA, Stevens PM, Deaton WJ, Miller RR. First pass radionuclide assessment of right and left ventricular ejection fraction in chronic pulmonary disease. Effect of oxygen upon exercise response. Chest. 1980;78(1):4-9.

65. Ashutosh K, Dunsky M. Noninvasive tests for responsiveness of pulmonary hypertension to oxygen. Prediction of survival in patients with chronic obstructive lung disease and cor pulmonale. Chest. 1987;92(3):393-399.

66. Oswald-Mammosser M, Weitzenblum E, Quoix E, et al. Prognostic factors in COPD patients receiving long-term oxygen therapy. Importance of pulmonary artery pressure. Chest. 1995;107(5):1193-1198.

67. Zielinski J, Tobiasz M, Hawrylkiewicz I, Sliwinski P, Palasiewicz G Effects of long-term oxygen therapy on pulmonary hemodynamics in COPD patients: a 6-year prospective study. Chest. 1998;113(1):65-70.

68. Ashutosh K, Phadke K, Jackson JF, Steele D. Use of nitric oxide inhalation in chronic obstructive pulmonary disease. Thorax. 2000;55(2): $109-113$

69. Vonbank K, Ziesche R, Higenbottam TW, et al. Controlled prospective randomised trial on the effects on pulmonary haemodynamics of the ambulatory long term use of nitric oxide and oxygen in patients with severe COPD. Thorax. 2003;58(4):289-293.

70. Baigorri F, Joseph D, Artigas A, Blanch L. Inhaled nitric oxide does not improve cardiac or pulmonary function in patients with an exacerbation of chronic obstructive pulmonary disease. Crit Care Med. 1999;27(10):2153-2158.
71. Archer SL, Mike D, Crow J, Long W, Weir EK. A placebo-controlled trial of prostacyclin in acute respiratory failure in COPD. Chest. 1996;109(3):750-755.

72. Saadjian A, Philip-Joet F, Paganelli F, Arnaud A, Levy S. Longterm effects of cicletanine on secondary pulmonary hypertension. J Cardiovasc Pharmacol. 1998;31(3):364-371.

73. Madden BP, Sheth A, Wilde M, Ong YE. Does Sildenafil produce a sustained benefit in patients with pulmonary hypertension associated with parenchymal lung and cardiac disease? Vascul Pharmacol. 2007;47(2-3):184-188.

74. Madden BP, Allenby M, Loke TK, Sheth A. A potential role for sildenafil in the management of pulmonary hypertension in patients with parenchymal lung disease. Vascul Pharmacol. 2006;44(5): 372-376.

75. Alp S, Skrygan M, Schmidt WE, Bastian A. Sildenafil improves hemodynamic parameters in COPD - an investigation of six patients. Pulm Pharmacol Ther. 2006;19(6):386-390.

76. Holverda S, Rietema H, Bogaard HJ, et al. Acute effects of sildenafil on exercise pulmonary hemodynamics and capacity in patients with COPD. Pulm Pharmacol Ther. 2008;21(3):558-564.

77. Stolz D, Rasch H, Linka A, et al. A randomised, controlled trial of bosentan in severe COPD. Eur Respir J. 2008;32(3):619-628.

78. Valerio G, Bracciale P, Grazia D'Agostino A. Effect of bosentan upon pulmonary hypertension in chronic obstructive pulmonary disease. Ther Adv Respir Dis. 2009;3(1):15-21.
International Journal of COPD

\section{Publish your work in this journal}

The International Journal of COPD is an international, peer-reviewed journal of therapeutics and pharmacology focusing on concise rapid reporting of clinical studies and reviews in COPD. Special focus is given to the pathophysiological processes underlying the disease, intervention programs, patient focused education, and self management protocols

\section{Dovepress}

This journal is indexed on PubMed Central, MedLine and CAS. The manuscript management system is completely online and includes a very quick and fair peer-review system, which is all easy to use. Visit http://www.dovepress.com/testimonials.php to read real quotes from published authors. 